\title{
Sound insulation of wooden floors
}

\author{
Artur Nowoświat ${ }^{1,}$, Rafał Żuchowski ${ }^{1}$, Michał Marchacz ${ }^{1}$ and Leszek Dulak ${ }^{1}$ \\ ${ }^{1}$ Silesian University of Technology, Faculty of Civil Engineering Department of Building \\ Engineering and Building Physics, Akademicka 5 Str., 44-100 Gliwice, Poland
}

\begin{abstract}
The objective of the article is to assess acoustic insulation of a wooden floor structure between stories in a pre-war residential building. The measurements involved acoustic insulation against impact sounds and airborne sounds. The article presents the results of acoustic tests for noninsulated floors and then for floors insulated with mineral wool. First, the results of the research were analyzed in terms of single-number acoustic insulation rates. These results were compared to the standards and findings described by other researchers. Then, an analysis was carried out for the processes as a function of frequency. The conclusions described in this article allow us to assess the applied acoustic insulation system.
\end{abstract}

\section{Introduction}

External walls, like all other envelopes in the building, including floors, are subjected to lateral sound transmission [1]. Acoustic insulation of buildings has an impact on the living comfort of people staying in these buildings. The said problem has been recently given more consideration along with the issue of heat transport, e.g. for mineral wool insulation [2]. Similar considerations regarding the correlation of thermal resistance and acoustic insulation were conducted by Nurzyński [3]. Apart from the acoustic insulation against airborne sounds, the comfort of people in buildings, including work and rest, greatly depends also on the acoustic insulation against impact sounds. The acoustic isolation against impact sounds is described by means of a single-number index describing a specific kind of "averaging" from all tertiary frequencies. It turns out, however, as described by Öqvist et al. [4] that even when the single-number rating by means of the $L_{n, w, R}$ index is positive, the sounds generated by walking, i.e. within the frequency range of $20-50 \mathrm{~Hz}$, can be very wearying. Such problems can occur in light structures [5]. Since in many countries buildings with wooden floors are still used, the problem of acoustics is being investigated all the time. Therefore, the authors of this publication decided to present the impact exerted by the application of mineral wool on improving the acoustic insulation of wooden floors.

\section{Acoustic insulation of the wooden floor}

Acoustic insulation of floors is determined both against airborne sounds and against impact sounds. For airborne sounds, we investigate the design index for the assessment of sound reduction, which is expressed by the following formula (1):

* Corresponding author: Artur.Nowoswiat@polsl.pl 


$$
R_{\mathrm{A} 1, \mathrm{R}}=R_{\mathrm{A}, 1}-2[\mathrm{~dB}]
$$

It is recommended to accept the value of $R_{A, 1}$ as determined on the basis of laboratory tests [6].

For impact sounds, we investigate the weighted index of normalized impact noise level $L_{\mathrm{n}, \mathrm{w}, \mathrm{R}}$. On the basis of his own analyses and available Polish literature, Dulak in his work [6] described the values of sound reduction indexes of exemplary wooden upper floor solutions, as shown in Figure 1.

a)

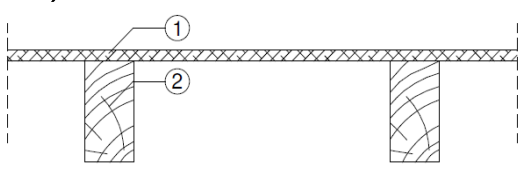

c)

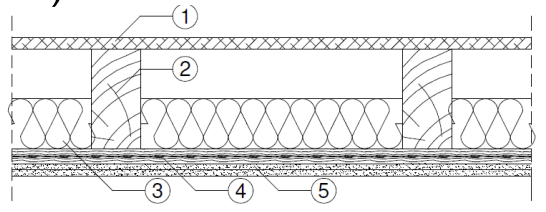

e)

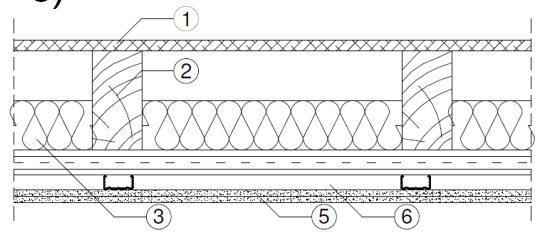

b)

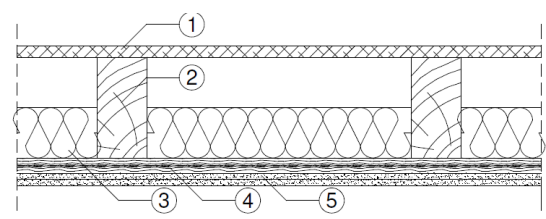

d)

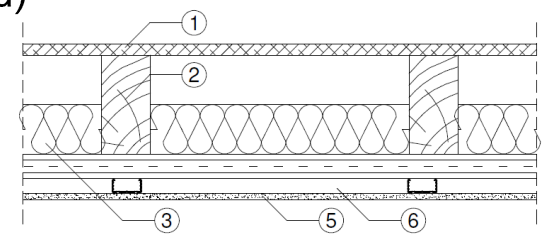

f)

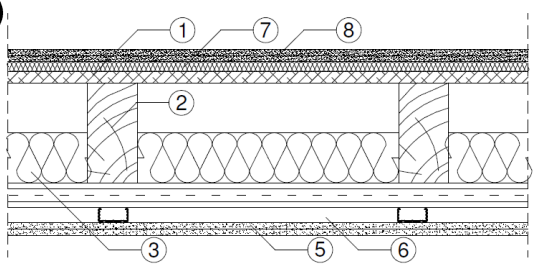

Fig. 1. Exemplary solutions of wooden floors 1) particle board $22 \div 24 \mathrm{~mm}$ thick, 2) wooden beams, e.g. 120/180, 3) mineral wool in mats with the thickness of approx. half the height of the beams, 4) wooden battens, e.g. 50/30, 5) plasterboard, 6) cold formed sections grate on spring joints, 7) mineral wool of possibly the lowest dynamic rigidity, e.g. $\mathrm{s}^{\prime} \leq 15 \mathrm{MN} / \mathrm{m}^{3}, 8$ ) dry screed, e.g. in the form of fiber-cement boards $2 \times 12.5 \mathrm{~mm}$.

The results of the research for the exemplary solutions presented in Figure 1 are quoted in the work [6]. Sound reduction indexes of the solution a) are respectively: $R_{\mathrm{Al}, \mathrm{R}}$ is within (20-25 dB), and $L_{\mathrm{n}, \mathrm{w}, \mathrm{R}}$ within $(93,88 \mathrm{~dB})$. For the solution b) $R_{\mathrm{Al}, \mathrm{R}} \in\langle 36,41 \mathrm{~dB}\rangle$, $L_{\mathrm{n}, \mathrm{w}, \mathrm{R}} \in\langle 78,75 \mathrm{~dB}\rangle$. The solution presented in Fig1. c) has the values $\Delta R_{\mathrm{Al}} \approx 2 \mathrm{~dB}$ and $\Delta L_{\mathrm{n}, \mathrm{w}} \approx 2 \mathrm{~dB}$ as compared to the solution b). The solution d) yields the results $R_{\mathrm{A} 1, \mathrm{R}} \in\langle 46,50 \mathrm{~dB}\rangle$, which compared to the solution b) gives the average improvement of $\Delta R_{\mathrm{A} 1} \approx 10 \mathrm{~dB}$ and $\Delta L_{\mathrm{n}, \mathrm{w}} \approx 8-15 \mathrm{~dB}$. The solution e) has the values $\Delta R_{\mathrm{A} 1} \approx 3 \mathrm{~dB}$ and $\Delta L_{\mathrm{n}, \mathrm{w}} \approx 5 \mathrm{~dB}$ as compared to the solution d). The solution f) is within $R_{\mathrm{Al}, \mathrm{R}} \in\langle 42,57 \mathrm{~dB}\rangle$, $L_{\mathrm{n}, \mathrm{w}, \mathrm{R}} \in\langle 52,56 \mathrm{~dB}\rangle$. 


\section{Methodology}

The sound insulation tests were carried out for the wooden floor between the first and the second storey in a pre-war multi-family building in Gliwice (Fig. 2).

a)

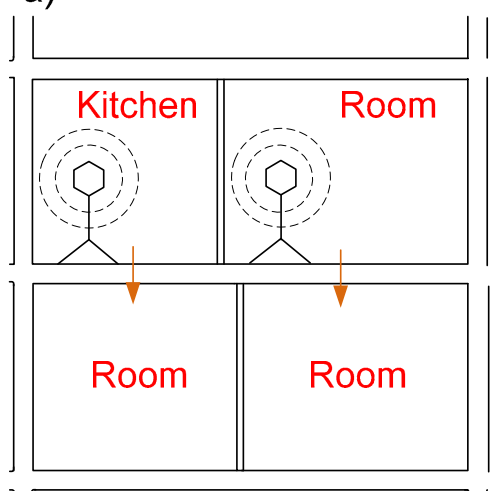

b)

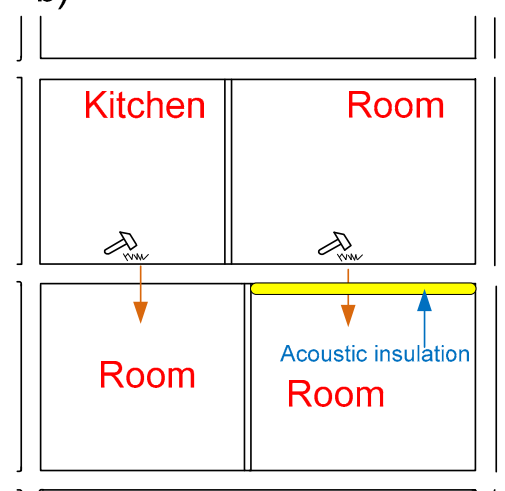

Fig. 2. Setup for the in situ tests of acoustic insulation against airborne sounds and impact sounds: a) wooden floor b) wooden floor with mineral wool filling.
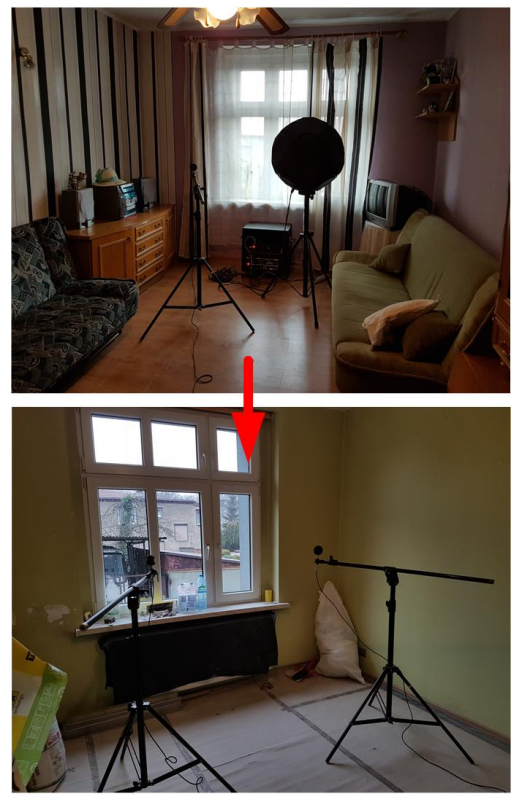

Fig. 3. A view of room layouts selected for field measurement of airborne sound insulation. Vertical downward transmission, wooden floor with acoustic adaptation $30 \mathrm{~cm}$ thick (Room-Bedroom - R').

The research was carried out for two situations. The first situation involved the wooden floor whereof the cross-section is presented in Figure 2a. The second situation concerned the same floor, but with mineral wool thermal insulation of the thickness of $30 \mathrm{~cm}$ (Fig. 2b). 


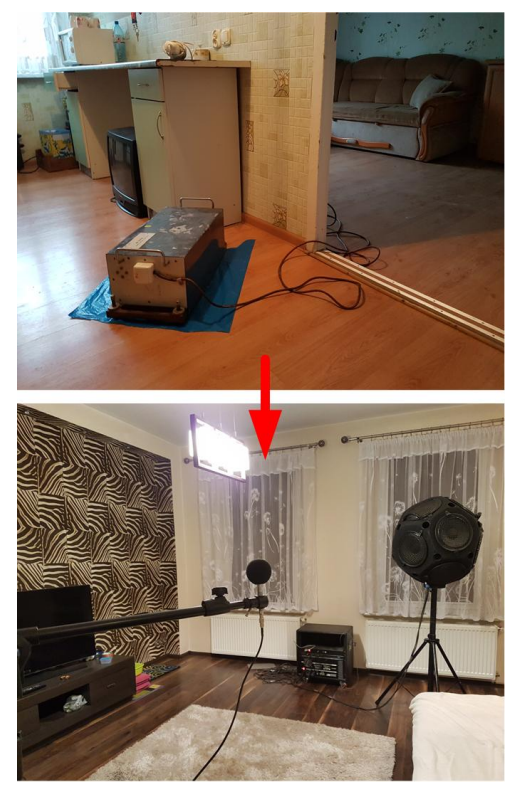

Fig. 4. View of room layouts selected for testing acoustic insulation against impact sounds. Vertical transmission downwards, wooden floor without acoustic adaptation (Kitchen - Living Room $-\mathrm{L}_{\mathrm{n}}$ ).

The tests were carried out using a measuring system whereof components met the metrological requirements for instruments of class 1accuracy.

The transmission part of the system consisted of the following elements:

- tapping machine which satisfied the requirements defined in the Standards [4],

- loudspeaker column with omni-directional radiation pattern,

- pink and white noise generator with amplifier.

The receiving part of the system included the following elements:

- four-channel SVAN 958 sound level meter,

- 1/2" microphone type SV22, 2 pcs,

- $1 / 2$ " microphone preamplifier type SV12L, 2 pcs,

- acoustic calibrator, type SV03A,

- a PC with the software SvanPC ++ Software Official 1.6.8.

In order to determine acoustic parameters of the envelopes, the reverberation time in the receiving room was determined. The research was carried out using the intermittent noise method in accordance with the guidelines included in the respective Standard [7]. The measurements were carried out for six microphone locations and two locations of sound source, which yielded the number of spatially independent measured decay curves equal to 12 . For each of the 12 microphone / loudspeaker locations, in order to reduce the measurement of uncertainty caused by statistical deviations, always 2 repetitions were made. For each of the 24 sound decay curves, the reverberation time was determined. The final result of the study was an arithmetic average. The results of the reverberation time measurements for the room without acoustic adaptation and with the applied adaptation are presented in Fig. 5.

To determine the parameters characterizing acoustic insulation between the rooms, measurement procedures were applied in accordance with the Standards referred to in Annex 1 to the Regulation [8]. Respectively for airborne sounds according to PN-EN ISO 140-4: 2000 [9] and for impact sounds according to PN-EN ISO 140-7: 2000 [10]. In the measurement process involving the determination of the approximate specific acoustic insulation, the transmitting and receiving rooms for each of the tested systems were 
selected according to the information contained in Figures 3 and 4. The measurements of the sound pressure level distribution as a function of frequency were carried out both in the receiving and transmitting rooms for 6 different microphone locations, and for two locations of the loudspeaker sphere. The final result was the averaged value obtained in the "energetic" manner for all completed measurements. For each of the measurement situations, the acoustic background was measured to allow for its potential impact on the value of acoustic insulation. The measurement results involving the sound pressure level in the transmission room and reception room as well as the averaged acoustic background level for the measuring systems between the kitchen and the room (floor without acoustic adaptation) and between the room and the room (floor with the built-in acoustic adaptation) are shown in Fig. 6.

In order to determine the influence of impact sound propagation between the dwellings, the layout of rooms as presented in Fig. 3 was selected. The measurements of the acoustic impact level were made for 4 different locations of the tapping machine and 4 locations of the microphone. The final result was the 'energetic' average for 8 location combinations of layout microphone-tapping machine. The locations of the tapping machine and microphone reflected the guidelines defined in the Standard [10]. For each of the measurement situations, the acoustic background was measured to allow for its impact on the value of acoustic insulation. The measurement results involving the level of sound pressure in the room and the averaged background noise for the situation between the kitchen and the room (floor without acoustic adaptation) and between the room and the room (floor with the built-in acoustic adaptation) are shown in Fig. 7 (the tapping machine was set directly on the flooring panels being the upper layer of the flooring structure).

\section{Results and discussion}

In the first place, reverberation times were determined in the receiving rooms, which are presented on the graphs a) and b) in Fig. 5. The reverberation time of a room can be defined as the time after which the sound pressure level drops by $60 \mathrm{~dB}$. There are many models applied to calculate the reverberation time [11] as well as measuring methods or approximation methods of the obtained results [12]. The research studies on reverberation time were carried out using the intermittent noise method. The final result was the average value from all measurements calculated for each central frequency separately.

a)

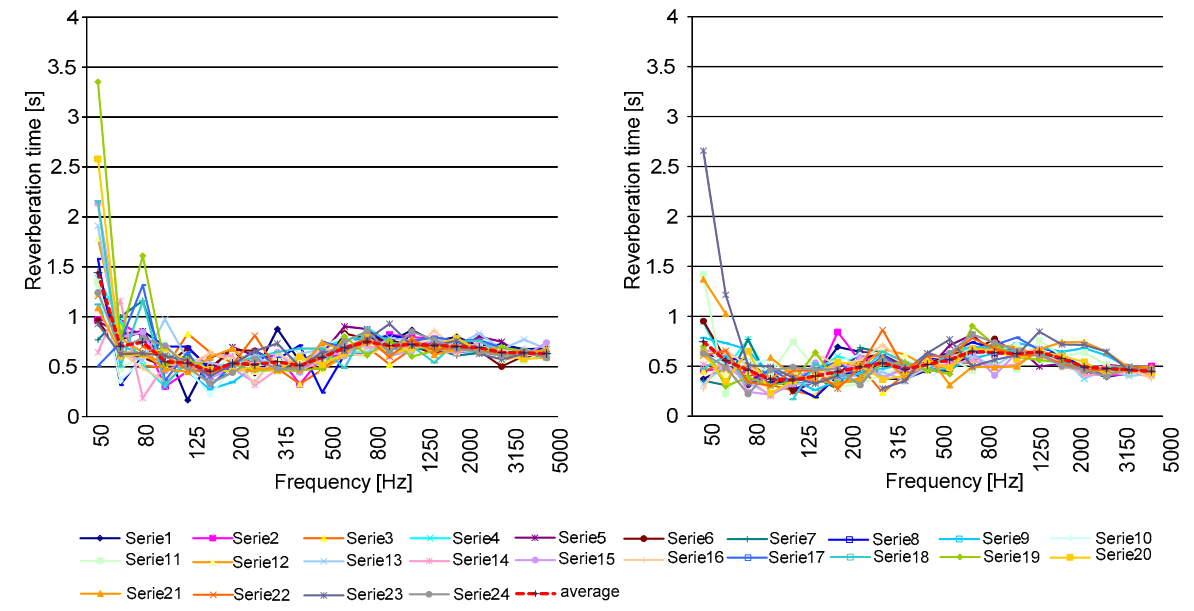

Fig. 5. Reverberation time of receiving rooms. a) under the wooden floor, b) under the floor with acoustic adaptation. 
The measurements involving the distribution of the sound pressure level as a function of frequency were carried out both in the receiving and transmitting room. The results of the measurements are presented in Figure 6.

a)

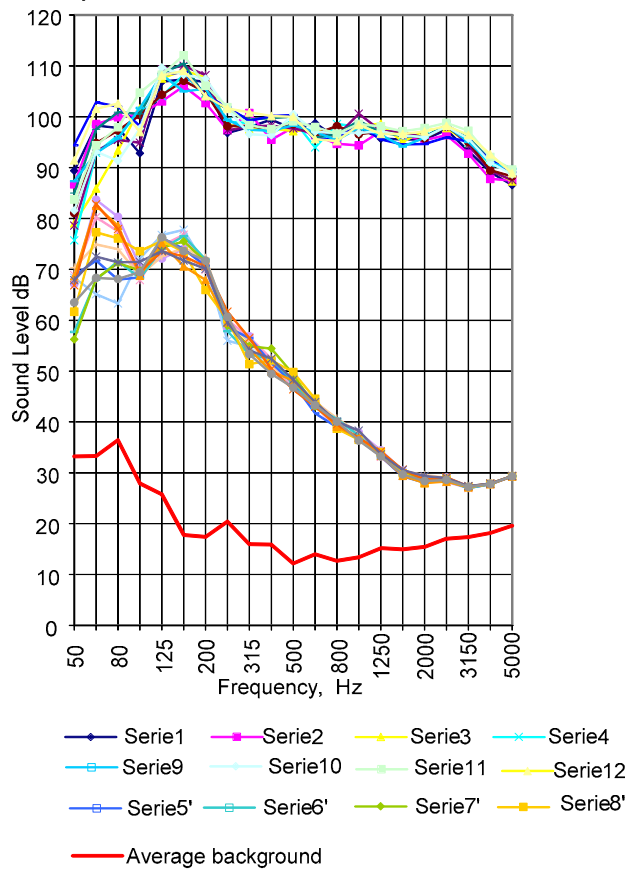

b)

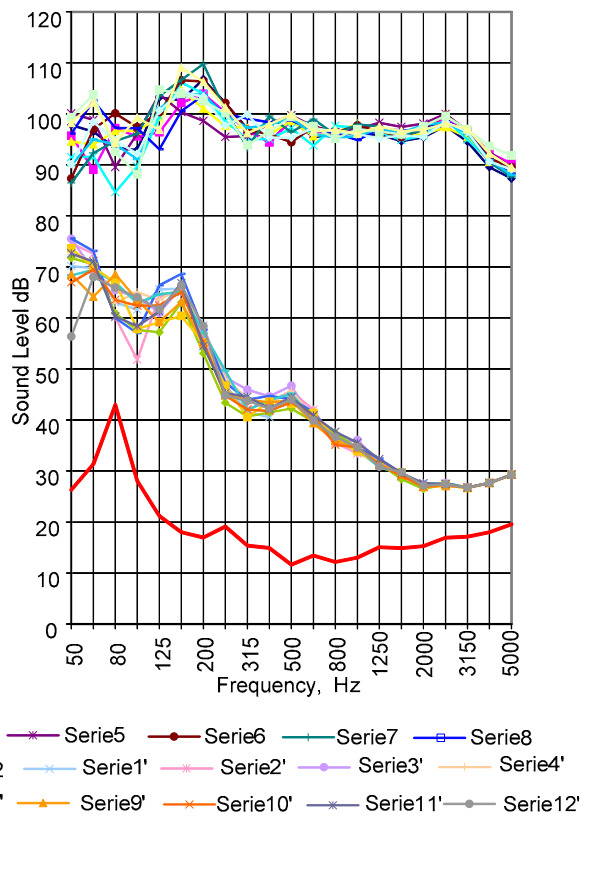

Fig. 6. Sound pressure levels as a frequency function in the transmission room $(1 \div 12)$ and in the reception room $\left(1^{\prime} \div 12^{\prime}\right)$ and the averaged level of acoustic background in $\mathrm{dB}$. Graph a) under the wooden floor, b) under the floor with acoustic adaptation.

We can observe, basing on the graphs presented in Figure 6 that the adaptation with mineral wool of the thickness of $30 \mathrm{~cm}$ contributed significantly to the reduction of sound pressure levels in the receiving room for low frequencies (from the range 50-200 Hz). That adaptation brought about the reduction of noise generated by walking. As observed by Öqvist et al. [4], low frequencies (walking) are most difficult to reduce.

The next series of measurements involved the propagation of impact sounds between residential dwellings. The measurements of impact sound level were made for 4 different locations of tapping machine. For each location of the taping machine, the results were recorded for 6 microphone layouts. The measurement results involving the noise generated by impact sounds are presented in Figure 7. 
a)

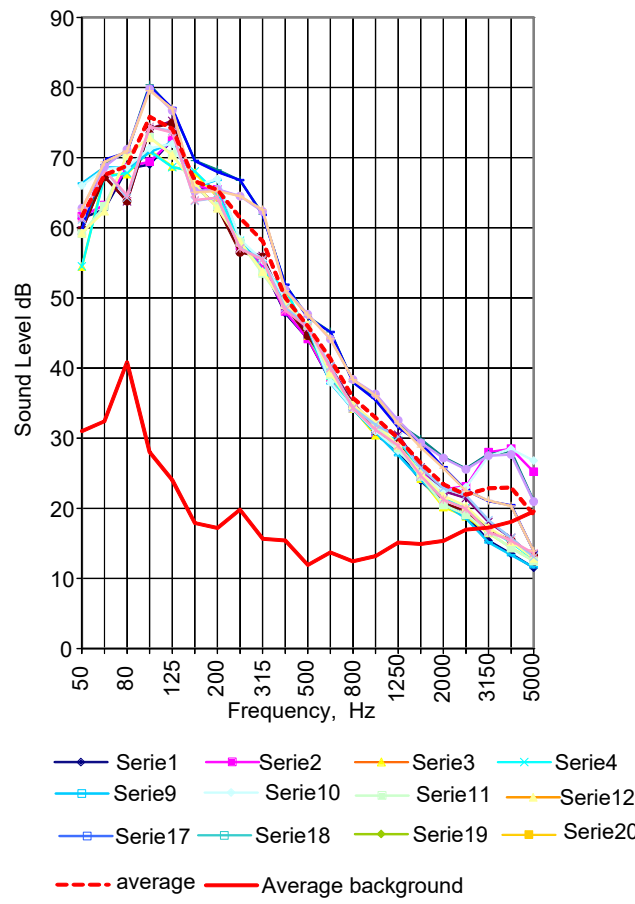

b)

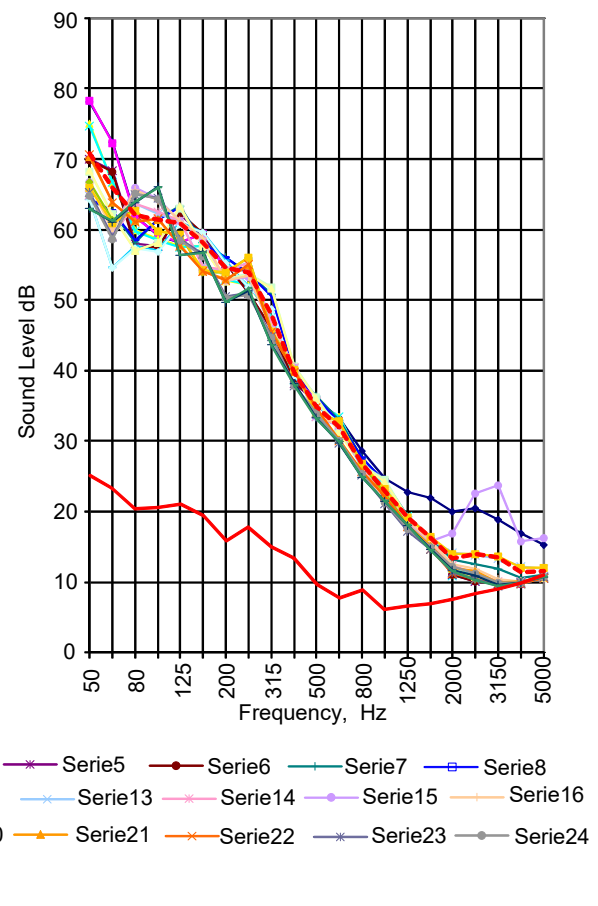

Fig. 7. Impact sound levels as a frequency function in the receiving room and the averaged level of acoustic background in $\mathrm{dB}$. Graph a) under the wooden floor, b) under the floor with acoustic adaptation.

Analogous to the graphs in Fig. 6, also the graphs in Fig. 7 demonstrate that the proposed acoustic adaptation proves effective for low frequencies, whereas for medium and high frequencies the adaptation does not significantly improve the results.

To provide the comprehensive evaluation, we present in Table 1 the results of acoustic insulation of the wooden floor without the adaptation and with the adaptation in the form of mineral wool as thermal insulation.

Table 1. Results of acoustic insulation against airborne and impact sounds.

\begin{tabular}{|l|c|l|}
\hline \multicolumn{1}{|c|}{ Floor } & \multicolumn{1}{|c|}{$\begin{array}{c}\text { Measurement } \\
\text { direction }\end{array}$} & \multicolumn{1}{c|}{ Results } \\
\hline $\begin{array}{l}\text { Wooden, without } \\
\text { adaptation }\end{array}$ & $\downarrow$ & $\begin{array}{l}\mathbf{L}_{\mathbf{n}, \mathbf{w}}^{\prime}=\mathbf{6 8}(-1) \mathrm{dB} \\
\mathbf{R}_{\mathbf{A 1}}^{\prime}=\mathbf{4 8 ~ d B}\end{array}$ \\
\hline Wooden, with adaptation & $\downarrow$ & $\begin{array}{l}\mathbf{L}_{\mathbf{n}, \mathbf{w}}^{\prime}=\mathbf{5 1}(-1) \mathrm{dB} \\
\mathbf{R}_{\mathbf{A 1}}^{\prime}=\mathbf{5 6} \mathrm{dB}\end{array}$ \\
\hline
\end{tabular}

We can observe based on Table 1 that the acoustic insulation indexes involving the airborne sounds and impact sounds have improved significantly. The improvement of acoustic isolation against airborne sounds is on the level of $\Delta R_{\mathrm{A} 1}^{\prime} \approx 8 \mathrm{~dB}$ and against impact sound $\Delta L_{\mathrm{n}, \mathrm{w}}^{\prime} \approx 17 \mathrm{~dB}$. It should be noted that after the adaptation, the insulation indexes meet the requirements for buildings in Poland. However, after a deeper analysis of the diagrams shown in Figures 6b) and 7b), we admit that that for low frequencies $\mathrm{f}<200 \mathrm{~Hz}$, the acceptable levels have been exceeded. 


\section{Conclusions}

Acoustic adaptation of wooden floors fulfills its function to a certain extent. We recommend introducing acoustic adaptation of the floor to attenuate noise in the range of low frequencies. The following conclusions can be drawn from this work:

1. The use of $15 \mathrm{~cm}$ thick mineral wool between the floor beams, lowering the ceiling and the use of another layer of $15 \mathrm{~cm}$ wool contributed to a significant improvement of the acoustic insulation of the floor against airborne sounds.

2. The use of the same adaptation as in point 1 allowed us to improve (reduce) the acoustic insulation index against impact sounds.

3. The improved insulation index against impact sounds does not allow for the exceeded values involving the sounds from low-frequency range ( $\mathrm{f}<200 \mathrm{~Hz}$ ).

4. An acoustic adaptation of the flooring should be applied to improve the indexes for low frequency sounds.

\section{References}

1. B. Szudrowicz, I. Iżewska, Archives of Acoustics 21(3), 299-309 (1996)

2. K. Miskinis, V. Dikavicius, A. Buska, K. Banionis, Applied Acoustics, 137, 62-68 (2018)

3. J. Nurzyński, Energy Procedia, 78, 152-157 (2015)

4. R. Öqvist, F. Ljunggren, R. Johnsson, Applied Acoustics, 135, 1-7 (2018)

5. K. Bodlund, J. Sound. Vib., 102(3), 381-402 (1985)

6. L. Dulak, Izolacje, 11-12, 42-49 (2017)

7. PN-EN ISO 3382-2:2010

8. Rozporządzenie Ministra Infrastruktury Dz. U. Nr 75, poz. 690 (In Polish)

9. EN ISO 140-4:2000

10. PN-EN ISO 140-7:2000

11. A. Nowoświat, M. Olechowska, Archives of acoustics, 41(1), 15-26 (2016)

12. A. Nowoświat, M. Olechowska, J. Ślusarek, Applied Acoustics, 106, 42-50 (2016) 